\title{
Hiking the roof of the world
}

\author{
Just a few simple preparations.
}

\section{Richard A. Lovett}

Courtney Brandt was having a nightmare when the music started. One moment she was floundering in a blizzard - lost, gasping for air that wasn't there: all the things that most emphatically were not going to happen. The next, she was hearing Pachelbel's Canon, which for some reason shed thought right for this, her first climb of a peak higher than Ben Nevis. Silly idea. Pachelbel wasn't Everest music. Even sillier had been reading a history chip of the days before smart fabrics and solar nets - the type of stuff that makes you think too much about the environment against which your equipment is designed to shield you.

Outside, that environment was making its own music: a symphony of moans, shrieks and wails as wind whipped through the South Col. But inside, the smart-tent was damping it nicely. The rental agent in Kathmandu had said the walls formed a $360 \times 360$ speaker web for reverse-phase damping, but however it worked, it reduced the outer world to a comforting murmur, like surf at her unde's beach house.

She stirred and the music died. So did the background damping, allowing her to fully appreciate the gale raging outside. It was hard to believe that in an hour it would be flat calm. But that was what the weather-control folks promised, and they always delivered.

Not that Everest hikers had the dout to order up weather, despite the extortionate permit fees. That was a by-product of monsoon control. Over in Bangladesh, farmers got bumper crops of rice. Here, hikers snagged six perfect days, although Courtney wished she'd not drawn a start time in the first wave. Rather than hiking to the col in sun, like the lucky folks still in the Base Camp car park, she'd had to ascend in weather nearly as bad as Scotland at its nastiest. Oh well, you didn't turn down Everest just because you got a crappy start time.

Already, she could hear the wind dying. She wanted nothing more than to get started, but the tent wasn't going to let her out until it ran her through an extended checklist, now displayed on a section of touch-fabric.

She acknowledged the first few panels with quick finger jabs. The batteries were fine. She'd brought her own solar net just to be on the safe side, but she was also plugged into the web of left-behind nets sprawling across half the col. Even with yesterday's clouds and two-dozen other parties using them, there'd been wattage to burn.

Next came the diagnostics for her thermal underwear. Dutifully, she checked the batteries - not that she'd be likely to need them. So long as she kept moving, the piezoelectric fabric would draw enough power from her body motion for the demon-pores to do their thing. That odd name, if she remembered correctly, had something to do with a guy named Maxwell. Powered by the combo of piezoelectrics, batteries and a solar-web knitted into her parka, the Maxwell filters would keep her warm by separating 'hot' air molecules from 'cold' ones. Turn them up too high, and you could cook yourself in Antarctica.

Finally came the oxygen web. More selective permeability, only this time chemical, not thermal. Oxygen in, everything else out. It made her look like a jungle explorer with a hat-brim of mosquito netting.

Unlike the tent, the $\mathrm{O}_{2}$ web wasn't pressurized. But with the oxygen confined to the vicinity of her face, there was no fire danger and you could dial it up to $100 \%$ if you wanted, which was undoubtedly what today would call for. As a backup, a tube ran beneath her nose, ready to feed oxygen

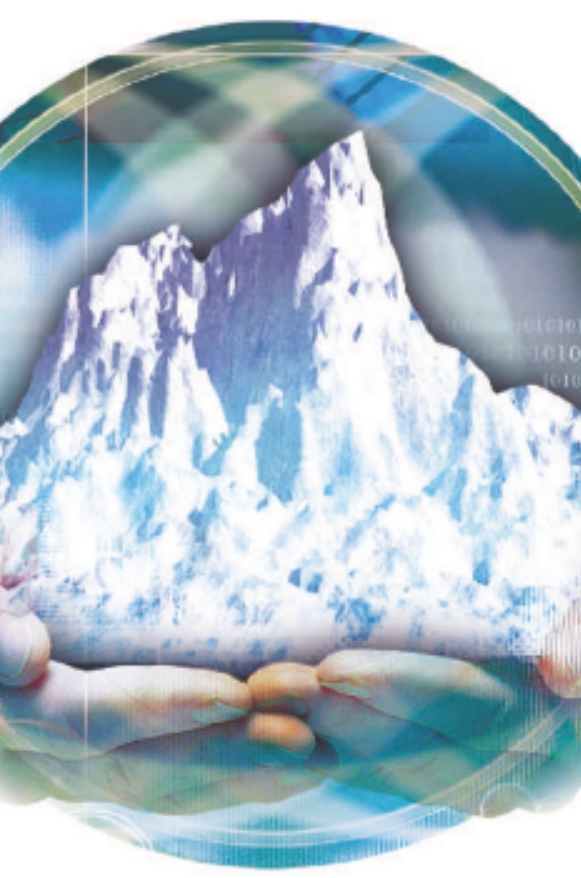

from a membrane in her scarf if the jungle-hat set-up failed. Her equipment had so many redundancies, in fact, that she wanted to yell at the tent to just forget them and let her go.

At last, when she'd swallowed the pills that increased her blood's affinity for oxygen, the tent agreed she was ready. A door formed from an invisible seam, the overpressure soughed out, and she slipped through behind it. Nearby, other climbers were emerging from their tents. Some were in pairs or trios, but most, like Courtney, were solo. She pushed the stud that extruded the crampons from her chemically heated boots, clipped onto the monofilament rope that led all the way to the summit, dialled her oxygen to max, and started to dimb. She was in good shape, and with plenty of oxygen, no worries about getting cold and no way to fall off, Everest wasn't really all that much tougher than Ben Nevis.

An hour later, she passed a group of purists. The night before, they'd refused to plug into any solar net other than the one they'd carried up themselves. That had restricted them to so little power that they'd had to use a dangerous-looking liquid-fuel stove rather than the microwave zappers favoured by everyone else. Courtney had been concerned enough to offer use of hers, but they'd refused.

Now, rather than wearing lightweight powersuits, they were bundled like giant puffballs - moving slowly, perhaps because of all that clothing, but more likely because they'd chosen some form of archaic equipment that didn't generate enough oxygen. Nor were they clipped

onto the monofilament. Instead, they carried their own rope as they trudged slowly upward.

Whisking by them as if they were standing still, Courtney couldn't think of anything to say, so she contented herself with a polite nod. She'd never understood such people. It was just a hike. Why make it tougher than it had to be?

Richard A. Lovett is an award-winning science and science-fiction writer from Portland, Oregon. Hehas written for dozens of magazines including New Scientist and The Economist. Hehas never been to Everest, buthas skied in Greenland. 